East African Medical Journal Vol. 85 No. 9 September 2008

MANAGEMENT OF SIMULATED PATIENTS WITH SEXUALLY TRANSMITTED INFECTIONS BY STAFF OF RETAIL PHARMACIES IN KIBERA SLUMS OF NAIROBI

Z. A. Kwena, BA, MA. (Geog), Social Scientist/Study Coordinator, Centre for Microbiology Research, Research, Care and Training Programme, Kenya Medical Research Institute, P. O. Box 614-40100, Kisumu, Kenya, A. Sharma, Sc.D, Freelance Consultant, P.M.B 69 Garki, Abuja, Nigeria, Minna, Nigeria, C. Muga, B.Ed, Social Scientist, Centre for Microbiology Research, Research, Care and Training Program Kenya Medical Research Institute, P. O. Box 19464-00202, Nairobi, Kenya, N. Wamae, MSPH, $\mathrm{PhD}$, IOD (K), Director, Centre for Microbiology Research, Kenya Medical Research Institute, P. O. Box 19464-00202, Nairobi, Kenya, E. A. Bukusi, MBChB, MMed. (Obs \& Gyn), MPH, PhD, Co-Director, Research, Care and Training Programme, Centre for Microbiology Research, Kenya Medical Research Institute, P. O. Box 19464-00202, Nairobi, Kenya

Request for reprints to: Mr. Z. A. Kwena, Center for Microbiology Research, Research, Care and Training Programme, Kenya Medical Research Institute, P. O. Box 614-40100, Kisumu, Kenya

\title{
MANAGEMENT OF SIMULATED PATIENTS WITH SEXUALLY TRANSMITTED INFECTIONS BY STAFF OF RETAIL PHARMACIES IN KIBERA SLUMS OF NAIROBI
}

\author{
Z. A. KWENA, A. SHARMA, C. MUGA, N. WAMAE and E. A. BUKUSI
}

\begin{abstract}
Objective: To evaluate the treatment suggested to sexually transmitted infections (STI) self-medicating patients in retail pharmacies.

Design: A descriptive cross-sectional survey.

Setting: Kibera slum, Nairobi City, Kenya.

Subjects: Staff of 50 convenient randomly selected retail pharmacies.

Results: The majority $(97 \%)$ of the pharmacy staff who attended to self-medicating patients asked questions. Most of these questions centered around the onset of the stated symptoms, the health of the partner, patient's current health status and previous medications taken. Of the 99 staff evaluated, $60 \%$ correctly diagnosed gonorrhoea and $82 \%$ correctly diagnosed genital ulcer disease (GUD). Only nine out of fifty (18\%) offered the recommended treatment for gonorrhoea and only one individual offered recommended treatment for GUD. The most commonly offered treatment for gonorrhoea and GUD was metronidazole and penicillin, respectively. Overall, only $10 \%$ correctly diagnosed both conditions and offered appropriate treatment. The staff also counselled patients on a wide range of issues including cond om use, abstinence and being faithful, contact treatment, seeking prompt treatment and completing treatment.

Conclusion: With only about $10 \%$ offering appropriate government recommended treatment for gonorrhoea and GUD, these pharmacy staff working in retail pharmacies in Kibera slum put slum dwellers seeking care at an increased risk of STI related morbidity and transmission due to inappropriate or inadequate treatment.

Recommendation: To improve management of these conditions, in-service training and enforcement of the relevant legislation and policy is needed.
\end{abstract}

\section{INTRODUCTION}

Because of increased health care costs at both public and private health facilities among other factors, the urban poor often resort to self-medication through purchase of medicines from retail pharmacies in their neighbourhoods $(1,2)$. Thus, retail pharmacies haveincreasingly become the first and sometimes the only contact of these people with allopathic health services. As such, these pharmacies are important sources of advice on disease diagnosis and treatment especially in developing countries where many drugpurchasing decisions maybe unmediated by medical professionals $(3,4)$. The World Health Organisation resolution number WHA 47.12 of 1994 recognises the key role pharmacy staff play in the health of the public and the use of medicines (5). To promote rational use of medication, retail pharmacies should have qualified staff, who can adequately diagnose conditions of self-medicating patients, offer adequate 
counselling and refer to other care where and as necessary. Unfortunately, staff in retail pharmacies of developing countries may not have basic professional training and / or experience (6-8). Hence, they may be unable to accurately diagnose diseases or prescribe appropriate treatment or advice. The situation is made worse by retail pharmacies situated in urban slum areas where the patient population may have limited options for informed choice.

Kenya'spolicythatregulatesretailpharmaceutical outlets requires that they should be run on day-to-day basis by a qualified pharmacist or medical doctor assisted by qualified pharmaceutical technicians (9). As part of the regulation, there should be a display of the necessary certifications including training qualifications of the pharmacists running the premise. However, it is commonly understood that due to laxity in the enforcement of this policy, many retail pharmacies, especially those situated in urban poor areas ignore regulation and engage staff who may not have appropriate qualifications but may accept lower remuneration.

Kibera the most populated slum settlement in Nairobi City harbours 25\% of the city's population and mostly those with lower incomes (10). High medical costs as well as distance and perceived lack of confidentiality may deter Kibera residents from seeking treatment in public clinics $(1,11)$. Consequently, this population may resort to selfmedication through purchase of medicines from retail pharmacies. Little information is available on the qualifications and competence of pharmacy staff of retail pharmacies in urban poor settlements in cities in developing countries.

\section{MATERIALS AND METHODS}

A cross-sectional survey was conducted using the mystery patient method to examine the management of STI self-medicating patients by retail pharmacy staff. We used gonorrhoea (GC) and genital ulcer disease (GUD) in men as tracer diseases. Ethical approval was obtained from Kenya Medical Research Institute's (KEMRI) Ethical Review Committee. After community mapping of retail pharmacies in Kibera slum, we selected a convenience sample of 50 retail pharmacies out of the 150 identified. Selection was based on their willingness to participate in the study. Two data collectors presented to the participating retail pharmacies as mystery patients seeking care for symptoms of either GUD or GC. We ensured a minimum of seven days between first and the second mystery patient's visit to the same retail pharmacy. At the target pharmacy, each mystery patient simulated one of the following scenarios to elicit required information:

(i) Simulated scenario 1 was "Ifeel sharpburning pain when passing urine. There is also thick yellowish discharge from my penis. What medicine should I take?" and,

(ii) Simulated scenario 2 was "I have several painful ulcersin my genitalia. They have smelly pus. What should I do?"

This resulted to a total of 100 encounters, 50 from each mystery patient. If the mystery patients were asked for additional information they provided the following details:

(i) He hasn't had any similar symptoms ever before.

(ii) He had had intercourse with a few different partners in the past few weeks.

(iii) He doesn't know whether any of the partners suffered from anything like this.

(iv) He had not seen a doctor about his problems and is willing to accept any suggestion that the pharmacy staff provides.

After the treatment was suggested and costed, the mystery patients indicated that they did not have enough money and left to look for money. They declined partial treatment if offered with a promise to return to buy the full dose. The mystery patients recorded data on how the retail pharmacy staff handled them as self-medicating patients presenting with symptoms of either GUD or GC in pre-coded observation record sheets within 10 minutes of leaving the target pharmacy.

The dataweremanually checked for completeness of the questionnairesand verification of the consistency of the responses given. It was then coded and doubleentered into SPSS program (Version 10.0, SPSS Inc., Chicago) for analysis. We compared treatment offered to mystery patients with the National guidelines issued by the Ministry of Health for syndromic management of STIs. The Government recommends the treatment of urethral discharge (gonorrhoea) with a combination of norfloxacine $800 \mathrm{mg}$ stat and doxycycline $100 \mathrm{mg}$ twice daily for seven days or alternatively a combination of spectimycin $2 \mathrm{~g}$ stat and doxycycline 100mg twice daily for seven days if the patient does not appropriately respond to first line treatment. For genital ulcer disease, the Government recommends a combination of erythromycin $500 \mathrm{mg}$ thrice daily for sevens days and an injection of benzathine penicillin $2.4 \mathrm{mu}$ stat. Patients allergic to penicillin are given erythromycin 500mg four times daily for 14 days. The alternative treatment to this is ceftriaxone $250 \mathrm{mg}$ stat.

\section{RESULTS}

Questions asked: After mystery patients presented both scenarios 1 and 2, 97\% of the pharmacy staff asked questions. Most of thestaff (94\%) asked questions about the onset of the symptoms. Other questions were on the health of the partner (77\%), requesting the patient togive more details on the problem (64\%), the patient's 
current health status (56\%), previous medicationstaken $(53 \%)$, sexual activities in the past $(14 \%)$, the period of time the patient had known the partner $(4 \%)$ and known allergy to any medication $(1 \%)$.

Diagnosis: Thirty out of fifty $(60 \%)$ of the staff of pharmacies visited correctly diagnosed scenario 1 as gonorrhoea while seven out of fifty (14\%) diagnosed it incorrectly as syphilis and others simply diagnosed it as an STD (12\%). About $82 \%$ of the staff of the pharmacies visited correctly diagnosed scenario 2 as genital ulcer disease that can be attributed to syphilis, genital herpes and / or chancroid (Table 1). The others (18\%) diagnosed it either as gonorrhoea, urinary tract infection and one staff was not sure what disease it was. Overall, $60-82 \%$ of the pharmacy staff correctly diagnosed gonorrhoea and GUD.
Medication offered for treatment: While $80 \%$ of the staff offered a drug regimen that included metronidazole to treat gonorrhoea, $48 \%$ offered a drug regimen that included benzathine penicillin injection to treat GUD (Table 2). A total of eighty six out of one hundred (86\%) of those who offered treatment for both conditions gave drug regimens with at least three different combinations. Whiletewnty seven out of thirty (90\%) of those who correctly diagnosed GC incorrectly offered metronidazolein their drug combinations, twenty three out of fourty (58\%) who had correct diagnosis of GUD offered drug regimen that included penicillin. Of those who offered doxycycline and norfloxacine in their drug regimen, nineteen out of thirty $(63 \%)$ and fourteen out of thirty $(47 \%)$, respectively had correct diagnosis of gonorrhoea. Other than penicillin, those who had correct diagnosis GUD offered: Doxycycline (30\%), erythromycin (28\%) and metronidazole $(18 \%)$.

Table 1

Diagnosis made by staff of retail pharmacies evaluated for scenario 1(GC) and scenario 2 (GUD)

\begin{tabular}{lcccc}
\hline \multirow{2}{*}{ Diagnosis } & \multicolumn{2}{c}{ Scenario } & (GC) & \multicolumn{2}{c}{ Scenario 2 (GUD) } \\
& Frequency & $(\%)$ & Frequency & $(\%)$ \\
\hline Gonorrhoea & 30 & 60 & 5 & 10 \\
Syphilis & 7 & 14 & 32 & 65 \\
Gonorrhoea and syphilis & 1 & 2 & 0 & 0 \\
Gonorrhoea and STD & 1 & 2 & 0 & 0 \\
Gonorrhoea or syphilis & 3 & 6 & 0 & 0 \\
STD & 6 & 12 & 0 & 0 \\
Syphilis or chancroid & 1 & 2 & 2 & 4 \\
Syphilis and STD & 1 & 2 & 0 & 0 \\
Chancroid & 0 & 0 & 6 & 12 \\
Urinary tract infection & 0 & 0 & 3 & 7 \\
Not sure & 0 & 0 & 1 & 2 \\
\hline Total & 50 & 100 & 49 & 100 \\
\hline
\end{tabular}

Table 2

Drugs offered for treatment of scenario 1 (gonorrhoea) and scenario 2 (GUD)

\begin{tabular}{lcccc}
\hline \multirow{2}{*}{ Drug } & \multicolumn{2}{c}{ Gonorrhoea } & \multicolumn{2}{c}{ Genital ulcer disease } \\
& Frequency & $(\%)$ & Frequency & $(\%)$ \\
\hline Metronidazole & 40 & 80 & 7 & 14 \\
Doxycycline & 26 & 54 & 12 & 25 \\
Ampicilin & 14 & 28 & 5 & 10 \\
Pain killers (Brufen and Paracetamol) & 15 & 30 & 2 & 4 \\
Tetracycline & 2 & 4 & 0 & 0 \\
Penicillin & 15 & 30 & 23 & 48 \\
Norfloxacin & 18 & 36 & 5 & 10 \\
Clotrimazole & 2 & 4 & 0 & 0 \\
Erythromycin & 13 & 26 & 11 & 22 \\
Ciprofloxacin & 3 & 6 & 2 & 4 \\
Other antibiotics & 2 & 4 & 5 & 10 \\
\hline
\end{tabular}


Partial treatment: Fourteen out of thirty $(47 \%)$ of those who correctly diagnosed GC offered government recommended medication but not in the recommended dose, frequency or duration of treatment. Similarly, three out of fourty $(8 \%)$ who had correct GUD diagnosis offered Government recommended treatment but not the correct dose, frequency or duration of treatment (Table 3). While none of the pharmacy staff who had incorrect diagnosis for GUD offered governmentrecommended treatment, five out of twenty (25\%) who had incorrect diagnosis for gonorrhoea, nonetheless, offered Government recommended treatment but not the correct dosage, frequency or duration of treatment. For patients who pleaded not to have enough money for the cost of drugs prescribed, $69 \%$ of the pharmacy staff accepted to give half treatment for the patients to come for the rest when they get the money, $25 \%$ were willing to give one drug to begin with as they look for more money. Only $4 \%$ insisted that the patients have enough money for complete treatment before they sell to them and $2 \%$ referred patients to a public health centre.
Government recommended drugs as those who had misdiagnosis. Likewise, one out of fourty (3\%) of the staff who had correct GUD diagnosis offered a regimen that included government recommended medicine for people who are allergic to penicillin or erythromycin 500mg four times daily for 14 days. Overall, only ten out of ninety nine $(10 \%)$ of the pharmacy staff offered appropriate treatment for both gonorrhoea and GUD.

Counselling patients: All pharmacy staff offered counselling except one. The counselling mostly centered on contact treatment $(84 \%)$, proper and consistent condom use (77\%) and completion of the treatment $(59 \%)$. They also counselled on seeking prompt treatment in future cases $(56 \%)$, being faithful to one partner $(47 \%)$, abstinence $(19 \%)$, correct use of medications $(17 \%)$ and as well counselled patients to go for a laboratory test or to see a doctor (9\%). Of the eight who had correct diagnosis of gonorrhoea and offered a government recommended treatment, all $(100 \%)$ counselled patients on condom use,

Table 3

Diagnosis and treatment offered without regard to correct dose, frequency and duration of treatment

\begin{tabular}{|c|c|c|c|c|}
\hline \multirow[t]{2}{*}{ Diagnosis } & \multicolumn{2}{|c|}{$\begin{array}{l}\text { Recommended treatment } \\
\text { (Drugs' strength ignored) }\end{array}$} & \multicolumn{2}{|c|}{$\begin{array}{c}\text { Other treatment } \\
\text { (Drugs' strength ignored) }\end{array}$} \\
\hline & Frequency & $(\%)$ & Frequency & $(\%)$ \\
\hline & \multicolumn{4}{|c|}{ Gonorrhoea (GC) } \\
\hline Correct diagnosis & 14 & 47 & 16 & 53 \\
\hline \multirow[t]{2}{*}{ Incorrect diagnosis } & 5 & 25 & 15 & 75 \\
\hline & \multicolumn{4}{|c|}{ Genital ulcer disease (GUD) } \\
\hline Correct diagnosis & 3 & 8 & 37 & 92 \\
\hline Incorrect diagnosis & 0 & 0 & 9 & 100 \\
\hline
\end{tabular}

Appropriate treatment: Eight out of thirty (27\%) of the pharmacy staff who had correctly diagnosed gonorrhoea offered a regimen that included government recommended medicines adhering to the correct dosage, frequency and duration. Paradoxically, one out of twenty $(5 \%)$ who had an incorrect diagnosis for gonorrhoea, nonetheless, offered the recommended treatment. Overall nine out of fifty $(18 \%)$ of the staff offered the mystery patients appropriate treatment for gonorrhoea. The pharmacy staff who had correct gonorrhoea diagnosis were more likely $(\mathrm{OR}=6.909)$ to offer a regimen containing government recommended drugs than those who did not although the difference observed was not statistically significant $(95 \% \mathrm{C} 1=0.97-60.36)$. Those who had correct diagnosis for gonorrhoea were 1.66 times as likely to offer a regimen that included
$88 \%$ on being faithful to one partner and contact treatment, and $63 \%$ counselled on abstinence. They also counselled on seeking prompt treatment (25\%), completing the treatment (25\%) and testing for HIV $(13 \%)$. The one individual, who correctly diagnosed GUD and offered a Government recommended treatment, counselled the patient on the use of condoms, seeking prompt treatment in future cases and completing the treatment.

\section{DISCUSSION}

The majority (97\%) of the pharmacy staff who attended to self-medicating patients asked questions. Most of these questions centered around the onset of the stated symptoms, the health of the partner, patient's current health status and previous 
medications taken. Of the 99 staff evaluated, $60 \%$ correctly diagnosed gonorrhoea and $82 \%$ correctly diagnosed GUD. Only nine out of fifty $(18 \%)$ offered the recommended treatment for gonorrhoea and only one individual offered recommended treatment for GUD. The most commonly offered treatment for gonorrhoea and GUD was metronidazole and penicillin, respectively. Overall, only $10 \%$ correctly diagnosed both conditions and offered appropriate treatment. The staff also counselled patients on a wide range of issues including condom use, abstinence and being faithful, contact treatment, seeking prompt treatment and completing treatment.

As per World Health Organisations (WHO) guidelines (PI6), proper history taking for correct STI diagnosis includes asking specific questions to clearly understand the nature of symptoms, onset and duration, recent sexual contacts, history of previous STDs and care-seeking of the current complaint to establish appropriate and adequate treatment (12). Thesestaff evaluated were comparable in history taking to pharmacy staff in Nairobi's sublocations covering medium, low and very low socioeconomic status of Kibera, Korogocho, Buruburu, Kawangware and Mathare (2). The questions asked of self-medicating patients were similar in the type of questions and details sought. However, the same study revealed that those who offered correct treatment were more. Additionally, about half of the pharmacy staff provided recommended treatment compared to only a tenth in this study. In other settings in Peru (13) even fewer pharmacy staff, approximately $1 \%$, provided correct syndromic treatment.

The Kenyan national guidelines for STI treatment emphasize provision of health information and prevention messages to patients. The health information is packaged in the form of $4 \mathrm{Cs}$; that is, promoting condom use, contact treatment, compliance and counselling patients. While nearly all pharmacy staff in Kibera counselled patients on condom use and asked about contact treatment, a similar study in Nairobi's medium, low and very low socio-economic estates (14) demonstrated that only between 18-48\% counselled patients on the two aspects. The differences in our findings may be partially due to different study design. While we focused primarily on retail pharmacies, the previous work included both retail pharmacies and other health outlets. Furthermore, while we used mystery patients, they used both mystery patients and interviewed service providers as well. Interviews of service providers may result in a provider bias that may not reflect actual practice.

Antibiotic resistance problem in Kenya may result from among other factors the laxity of enforcing the rules that restrict 'prescription only' drugs. This is likely to exacerbate the growing instances of treatment failures $(15,16)$. Most of the pharmacy staff offered drugs that were not recommended for present conditions, and unfortunately even those who offered the recommended drugs did not give correct dose, frequency or duration. This points to a potentially serious problem that could contribute to resistance and treatment failures. This occurs despite the Government's elaborate syndromicSTI treatment guide that is distributed free of charge by National AIDS and STDs Control Program (NASCOP) to assist medical staff (17). This scenario points to a need for more access of these guidelines and a review of law enforcement mechanisms for establishment and licensing of pharmacists.

Although the results of this study reveal that pharmacy staff performed relatively well in history taking of the conditions patients presented, they did not perform as well in diagnosing the various conditions based on the patients' account. It is of great concern that only a tenth offered appropriate treatment for the two STI conditions presented. Given the role that early STI treatment plays in HIV prevention, our findings suggest thatSTIself-medicating patients may not access appropriate treatment in such settings. This could contribute to fuelling the HIV pandemic since the role of STI management as a HIV prevention tool is well documented (18). One way to improve the quality of care self-medicating patients receive from retail pharmacies in slum areas is training of pharmacy staff in management ofSTI in addition to enforcement of legislation on the sale and procurement of restricted medications like antibiotics and other medications designated as 'prescription only'.

In conclusion, with only about $10 \%$ offering appropriate Government recommended treatment for gonorrhoea and GUD, pharmacy staff working in retail pharmacies in Kibera slum put slum dwellers seeking care at an increased risk ofSTI related morbidity and transmission due to inappropriate or inadequate treatment. Building on the fact that these pharmacy staff demonstrate professionalism in taking history of the conditions presented and that approximately three fifths are able to correctly diagnose at least one of these two STIs, additional in-service training might be appropriate to improve management of these conditions. In addition, enforcement of the legislation and policy by appropriate bodies is clearly warranted.

\section{ACKNOWLEDGEMENTS}

To the Director KEMRI, Norton S. Mutai and Charity W. Maingi for their support and advice. All the staff of the sampled pharmacies for their participation. The paper has been published with the permission of Director, KEMRI.

Funding: Organization of Social Science Research in Eastern and Southern Africa (OSSREA) Small Grants Program. 


\section{REFERENCES}

1. Kamaara, E. The Effects of structural adjustment programs on women's health in Kenya. In: Africa in Transformation (ed) Prah, K.K and Ahmed, A.G.M. Addis Ababa, OSSREA. 2000.

2. Voeten,H.A.C.M.,Otido,J.M.,O'Hara,H.B., etal. Quality of sexually transmitted diseases case management in Nairobi, Kenya. Sex Transm. Dis. 2001; 633-642.

3. Goel, P.K., Ross-Degnan, D., McLaughlin, T.J. and Soumerai, S.B. Influence of location and staff knowledge on quality of retail pharmacy prescribing for childhood diarrhea in Kenya. Int. J. Qual. Health Care. 1996; 8: 519-526.

4. Ross-Degnan, D., Soumerai, S.B., Goel, P.K., et al. The impact of face-to-face educational outreach on diarrhoea treatment in pharmacies. Health Policy Plan. 1996; 11: 308-318.

5. WHO. Public Education in Rational Drug Use: A Global Survey, 1997

6. Turner, A.N., Ellertson, C., Thomas, S., and Garcia, S. Diagnosis and treatment of presumed STIs at Mexican pharmacies: Survey results from a random sample of Mexico City pharmacy attendants. Sex Transm. Infect. 2003; 79: 224-228.

7. Chalker, J., Chuc, N.T., Falkenberg, T., Do, N.T. and Tomson, G.STD management by private pharmacies in Hanoi: practice and knowledge of drug sellers. Sex Transm. Infect. 2000; 76: 299-302.

8. Rogers, A., Hassell, K., Noyce, P. and Harris, J. Advicegiving in community pharmacy: Variations between pharmacies in different locations. Health Place. 1998; 4: 365-373.

9. Government of Kenya. Kenya National Drug policy, Ministry of Health. Government printers, Nairobi. 1994.
10. Majtenyi, C. Is modernity an enemy of morality? J. Soc. Relig. Concern. 16: 2001.

11. Nganda, B. Urbanization and health service delivery in Kenya: the challenges for the City of Nairobi. Workshop Report No. 14/2002. Centre for Basic Research. Kampala: 17-21.

12. WHO. Evaluation of national AIDS programs: A method's package of prevention of HIV infection. WHO/GPA/TCO/SEF/94.1, 1994.

13. Garcia, P., Hughes, J., Carcamo, C., et al. Training pharmacy workers in recognition, management and prevention of STDs: District randomized control trial. Bull. World Health Organ. 2003; 81: 806-814.

14. O'Hara, H.B., Voeten, H.A.C.M., Kuperus, A.G., et al. Quality of health education during STD case management in Nairobi, Kenya. Int. J. STD AIDS 2001; 12: 315-323.

15. Berkley, J.A., Maitland, K., Mwangi, I., Ngetsa, C., et al. Use of clinical syndromes to target antibiotic prescribing in seriously ill children in malaria endemic area: observational study, Brit. Med. J. 2005; 330: 995.

16. Kariuki, S., Arthur, G. and Muyodi, J. Increased antibiotic resistance in non-typhi Salmonella from bacteremic HIV-seropositive patients (1997-99) compared to 1990-94. Int. Conf. AIDS. 2000 Jul 9-14; 13:(abstract no. MoPeB2258).

17. Government of Kenya. Management of sexually transmitted diseases (STDs). Government printer, Nairobi, 2002.

18. Steen, R. Eradicating chancroid, Bull. World Health Organ. 2001; 79: 818-826. 